To the Editors:

\title{
Adherence to tobacco control policy implementation: a cross sectional study in a selected area in Ragama town, Sri Lanka
}

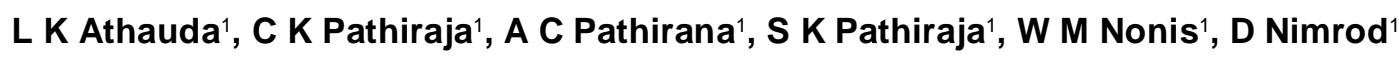 \\ Ceylon Medical Journal 2019; 64: 34-35
}

DOI: http://doi.org/10.4038/cmj.v64i1.8826

Sri Lanka was the first Asian country to ratify the World Health Organization (WHO) Framework Convention of Tobacco Control (FCTC) in 2003. Initiated by this undertaking, the National Authority for Tobacco and Alcohol (NATA) Act No 27 of 2006, the first legislature for tobacco control was enacted in parliament, with provisions for advertising, sales and promotion regulations for tobacco and creating smoke free environments in the country [1].

Despite anti-smoking regulations being in place for indoor public places, high levels of indoor air pollution have been recorded in restaurants [2]. NATA authorized officers have also identified the need for stronger monitoring and evaluation processes and community support in enforcing the Act [3]. Amidst the staggering global evidence on public health problems associated with tobacco smoking and limited evidence on regional or national level tobacco policy implementation in Sri Lanka, this study aimed to observe the implementation of tobacco control legislature based on the NATA Act No. 27 of 2006 in the Ragama town, Sri Lanka.

We conducted non-participatory, direct observations based on a pre-prepared checklist and an interviewer administered survey, independently. The study setting included five public places and 11 commercial establishments in the Ragama town.

Researchers randomly approached adult persons at public places, commercial establishments and on the street in the Ragama town and executed a quick interviewer administered questionnaire with their informed consent. An observation checklist was prepared based on a WHO report [4] and relevant components of the NATA Act No. 27 of 2006. Two researchers independently reported observations on a 15 -item checklist which included 12 items dedicated for commercial establishments and three for public places. Observations were done discreetly and recorded immediately afterwards.

The questionnaire assessed the awareness level of the NATA Act regulations specified in which were given a score from zero to 19 . The study was approved by the Ethics Review Committee, Faculty of Medicine, University of Kelaniya (P/196/12/2016).

We observed all public places in the Ragama town area, including the railway station, private and public bus stands, post office and the Colombo North Teaching Hospital premises. Tobacco was not sold or promoted at any of the above. 'NO SMOKING' signs were available only at the railway station. Smoking, however, was observed at the North Colombo Teaching Hospital premises, as well as public and private bus stands $(\mathrm{n}=3$, 60\%) (Figure 1).

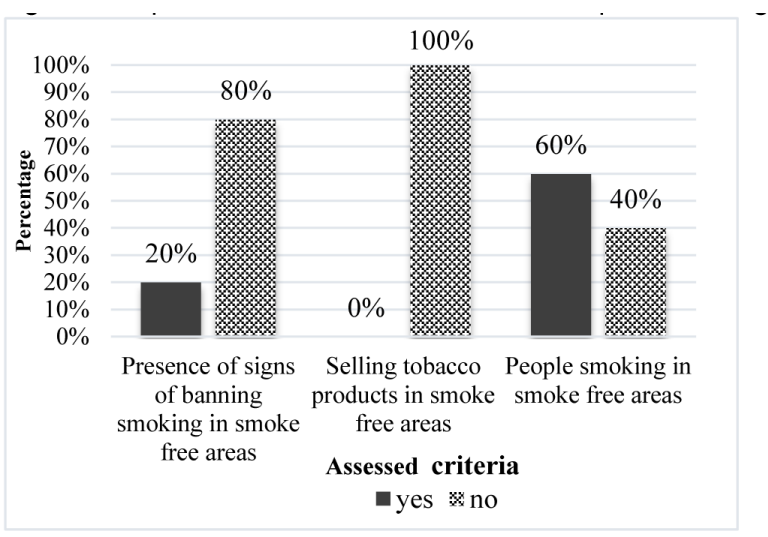

Figure 1. Implementation of NATA Act at public places in Ragama town.

${ }^{1}$ University of Kelaniya, Sri Lanka.

Correspondence: LKA, e-mail: <lathika@kln.ac.lk>. Received 21 December 2018 and revised version accepted 11 March 2019. 
We observed eleven randomly selected commercial establishments in the Ragama town including, restaurants, hotels, grocery stores, and supermarkets. Tobacco was sold in six locations (54.5\%), of which only two (18.8\%) had a notice for minimum purchase age while one provided supportive facilities for smoking (Figure 2). A male actor who purchased cigarettes was not asked for age confirmation at any of the above six locations.

Of the 384 participants of the survey $59.9 \%(n=230)$ were males and $40.1 \%(n=154)$ were females. Participants' age ranged from 18 to 87 years, while $10.6 \%(n=33)$ were employed at public or commercial establishments. Seventy two percent of the general public $(\mathrm{n}=311)$ and $70 \%$ of commercial and public institution employees achieved a good score (12 or above out of 19) on awareness of tobacco control legislation.

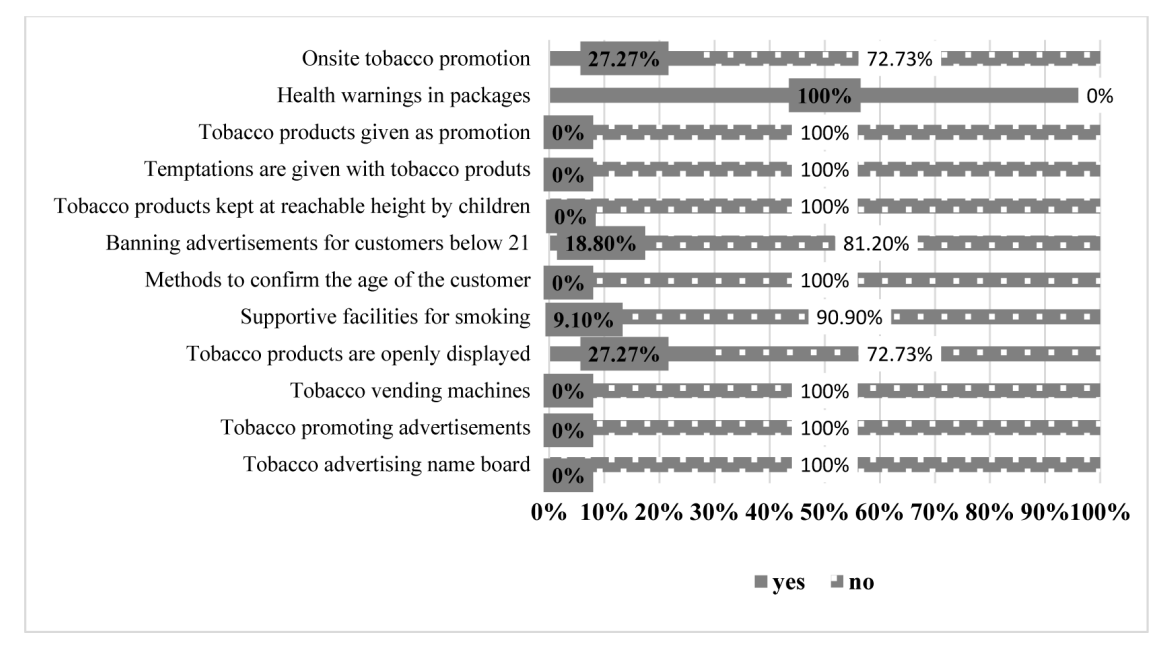

Note: Public Places : any place to which the public have access, whether as of right or otherwise (1).

Figure 2. Implementation of NATA Act in commercial establishments.

Although limited to a single location, as a student project, this study attempted to methodically observe policy implementation. People of Ragama town were well aware of national tobacco control regulations. While scoring at medium compliance level for tobacco control nationwide by WHO in 2017, [4] this study identified that policy implementation in Ragama had room for improvement. Therefore, this calls for further studies on tobacco policy island wide and community support on implementation for better tobacco control in the country.

\section{Acknowledgements}

We would like to acknowledge the Department of Public Heath, Faculty of Medicine, University of Kelaniya for research support, and the participants for their enthusiasm.

\section{Funding}

No funding received.

\section{Conflict of interest}

\section{References}

1. Government Publications Bureau. National Authority on Tobacco and Alcohol Act, No. 27 of 2006. Colombo, Sri Lanka: Parliment of the Democratic Socialist Repubic of Sri Lanka; 2006 p. 0-25.

2. Nandasena S, Wickremasinghe AR, Lee K, Sathiakumar N. Indoor fine particle (PM2.5) pollution exposure due to secondhand smoke in selected public places of Sri Lanka. Am J Ind Med 2012; 55(12): 1129-36.

3. Pallewaththa P, Niwarthana H, Nanayakkara S. Explore perceptions on enactment of the National Authority on Tobacco and Alcohol Act No.27 of 2006 (NATA) among authorised officers in Sri Lanka. Research Symposium on Combatting Alcohol, Tobacco and Other drugs in National Development. Colombo, Sri Lanka: Alcohol and Drug Information Centre; 2015.

4. World Health Organization, WHO report of the Global Tobacco Epidemic, 2017. Country Profile Sri Lanka. 2017. 